\title{
Pregnancy-associated Spontaneous Pneumomediastinum: A Contemporary Review
}

\author{
Narcisse O. Amine ${ }^{1}$, Christine M. Lomiguen ${ }^{2}$, Asma Iftikhar ${ }^{3}$, Sonu Sahni ${ }^{4}$ \\ 1. Department of Primary Care, Touro College of Osteopathic Medicine, New York, USA 2. Department of Anatomy, \\ Touro College of Osteopathic Medicine, New York, USA 3. Department of Pulmonology, New York Presbyterian Hospital \\ Queens, New York, USA 4. Department of Internal Medicine, Brookdale University Hospital Medical Center, New York, \\ USA
}

Corresponding author: Sonu Sahni, sonu.sahni@touro.edu

\begin{abstract}
Spontaneous pneumomediastinum (SPM), also referred to as mediastinal emphysema, is defined as the presence of free air in the mediastinal cavity without a clear and identifiable cause. Spontaneous pneumomediastinum, in general, is a relatively rare condition, more so in the setting of pregnancy or labor. Clinically, SPM may present as dyspnea, chest pain, and subcutaneous swelling, which may be of serious concern in the setting of pregnancy. A comprehensive literature review revealed that the majority of patients are primiparas, of a younger age, and have term or longer durations of pregnancy. The second stage of labor was found to be most commonly associated with the development of SPM. The pathomechanism suggests that performing the Valsalva maneuver during the active stages of labor may play a role in the development of SPM. Once diagnosed, patients with SPM in pregnancy are admitted to the hospital, treated conservatively, and followed until resolution. SPM must be diagnosed and managed promptly due to rare but serious complications. In addition, dyspnea or chest pain with an unknown etiology should include SPM in the differential diagnosis, especially in the setting of pregnancy and labor.
\end{abstract}

Categories: Emergency Medicine, Obstetrics/Gynecology, Pulmonology

Keywords: spontaneous pneumomediastinum, pneumomediastinum, pregnancy, labor, subcutaneous emphysema, dyspnea, chest pain

\section{Introduction And Background}

\section{Introduction}

Pneumomediastinum (PM) is defined as the presence of free air in the mediastinal cavity, which was originally described by Laënnec in 1819 [1]. Pneumomediastinum is most commonly seen secondary to a known cause, such as blunt force trauma or iatrogenic in nature (i.e. endoscopic procedures or central line placement). However, PM without a clearly defined etiology is termed spontaneous pneumomediastinum (SPM). SPM, though with the moniker "spontaneous," may occur due to various physiologic or pathologic processes. It is most often seen in the setting of underlying pulmonary conditions, such as asthma,

Received 09/28/2018

Review began 10/03/2018 Review ended 10/07/2018 Published 10/15/2018

\section{() Copyright 2018}

Amine et al. This is an open access article distributed under the terms of the Creative Commons Attribution License CC-BY 3.0., which permits unrestricted use, distribution, and reproduction in any medium, provided the original author and source are credited. interstitial lung disease, or chronic tobacco use [2]. A physiologic process in which SPM may occur is in the setting of pregnancy, labor, and delivery. Though it is a rare occurrence, it may indicate other, possible, serious underlying pathologies. Its clinical presentation is also often confused with that of other chronic pulmonary conditions and may remain undiagnosed. Herein, the authors attempt to summarize the entity of SPM in the setting of pregnancy through a case and literature review. The goal is to form an awareness of the clinical presentation and course of SPM in pregnancy. The findings of our comprehensive review are presented along with a review of the literature outlining the clinical presentation, diagnostic algorithm, as well as the therapeutic process in the setting of SPM.

\section{Methods}

A search was conducted of the National Library of Medicine's MEDLINE/PubMed databases, with the objective of identifying all articles published in the English language between January 1980 and May 2018 with "spontaneous pneumomediastinum" or "mediastinal emphysema” in conjunction with "pregnancy" or "labor." Combinations of medical subject heading terms associated with spontaneous pneumomediastinum in pregnancy or labor were also searched, including "postpartum pneumomediastinum," "peripartum pneumomediastinum," and “obstetric mediastinal emphysema.” We mainly selected publications that were recently published but did not exclude any relevant older manuscripts. We also searched the reference lists of all articles identified by this search strategy and selected those judged to be relevant. All pertinent literature was retrieved, analyzed, and thoroughly searched in order to identify any potential additional manuscripts that could be referenced. All data were accessed between January and June 2017. Our comprehensive PubMed/MEDLINE search revealed a total of 184 manuscripts, of which duplicates, articles not of the English language, or not related to our focus were excluded. This yielded a total of 44 manuscripts that were completely assessed and incorporated into this review. 


\section{Cureus}

\section{Review}

\section{Pregnancy and pneumomediastinum}

The mediastinal cavity is delineated laterally by the pleural cavities, inferiorly by the diaphragm, superiorly by the thoracic inlet, anteriorly by the sternum, and posteriorly by the thoracic vertebrae. The structures encompassed in the mediastinum are primarily cardiac in nature, including the heart, pericardium, as well as the great vessels. Pneumomediastinum refers to the presence of free air within the mediastinal cavity. SPM, initially described by Laennec in 1819, was further characterized in a case series by Hamman in 1939 [3]. Radiologic findings have been shown in Figures 1-2. Spontaneous pneumomediastinum, in general, is a relatively rare condition with a reported incidence of less than 1:44,000 and in the setting of pregnancy or labor, approximately 1:100,000 [4-5]. Though many pre-existing medical conditions have been thought to predispose to the development of SPM, the pathophysiologic process is the same [2].

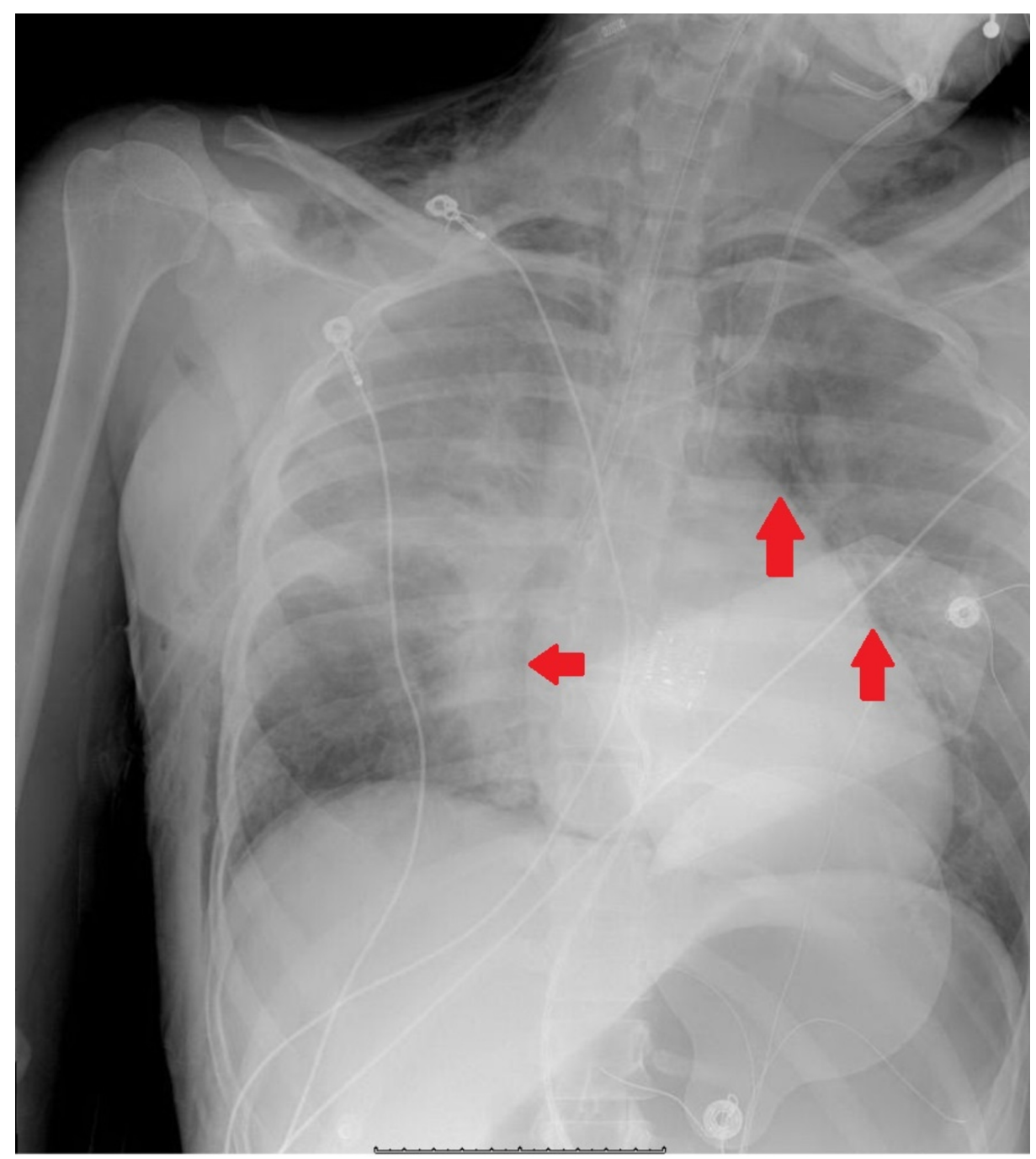

FIGURE 1: Chest X-ray showing the presence of pneumomediastinum Red arrows point to free air around the heart silhouette. 


\section{Cureus}

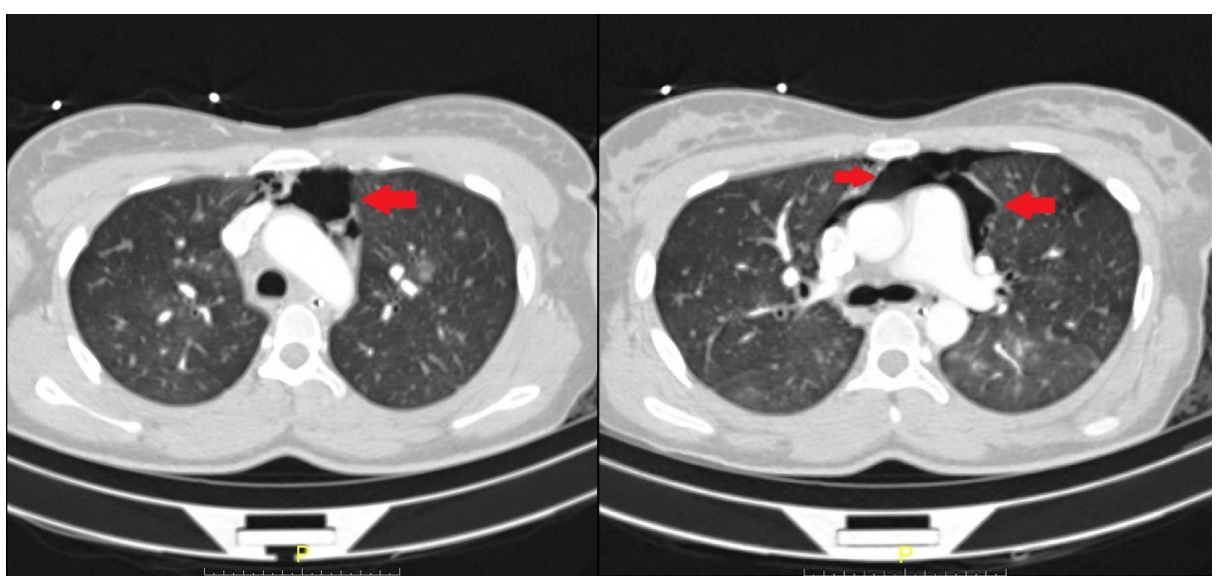

FIGURE 2: Computer tomography showing the presence of free air in the mediastinum anterior to the heart and great vessels

Red arrows point to the pockets of free air in the mediastinal cavity.

Theory has it that sudden changes in intrathoracic pressure may precede the development of SPM. The pathogenesis of SPM was first proposed by Macklin in 1939. His proposed mechanism was that alveolar ruptures lead to air dissection along bronchovascular sheaths with the eventual spreading of this inspired air into the mediastinum [6]. This was later coined the "Macklin Effect" in 1944, which broke down the formation of PM into a linear process beginning with alveolar ruptures, leading to air dissecting along bronchovascular sheaths and culminating with the spread of interstitial emphysema into the mediastinum [7]. In the setting of pregnancy, it has been theorized that the Valsalva maneuver produced associated with the second stage of labor may cause a rupture of the alveoli leading to this condition and the propagation of the Macklin effect.

There are four stages of labor. The first stage lasts from the onset of true labor to complete dilation of the cervix. The second stage spans from a complete dilation of the cervix to the birth of the baby. The third stage lasts from the birth of the baby to the delivery of the placenta. The fourth stage spans from the delivery of the placenta to the stabilization of the patient's condition, usually at about six hours postpartum [8]. SPM is most often seen in the second stage of labor and does not negatively affect the following pregnancies. This may due to the "pushing" and strain faced in this stage of labor.

\section{Pathophysiology}

As mentioned, the Valsalva maneuver has been implicated in the development of SPM. The Valsalva maneuver is a forced expiratory effort against a closed glottis, which results in a change in intrathoracic pressure, affecting venous return, cardiac output, arterial pressure, and heart rate. During Valsalva, the intrathoracic pressure becomes positive due to the compression of the thoracic organs. Of the various explanations for pneumomediastinum in pregnancy, the most widely accepted theory implicates the rupture of marginal pulmonary alveoli as a result of repetitive overinflation of the lungs and of high intra-alveolar pressures during the second stage of labor [9]. In maternal delivery efforts, constant pushing during labor consequently results in increased intrathoracic pressure in the presence of decreased vascular caliber; this establishes a pressure gradient in the vascular sheath, which allows air to dissect into the mediastinum. From the mediastinum, air migrates along the fascial planes into the subcutaneous and retroperitoneal tissues [10-11]. An outline of this process has been shown in Figure 3 [12]. 
Pathophysiology of Spontaneous Pneumomediastinum

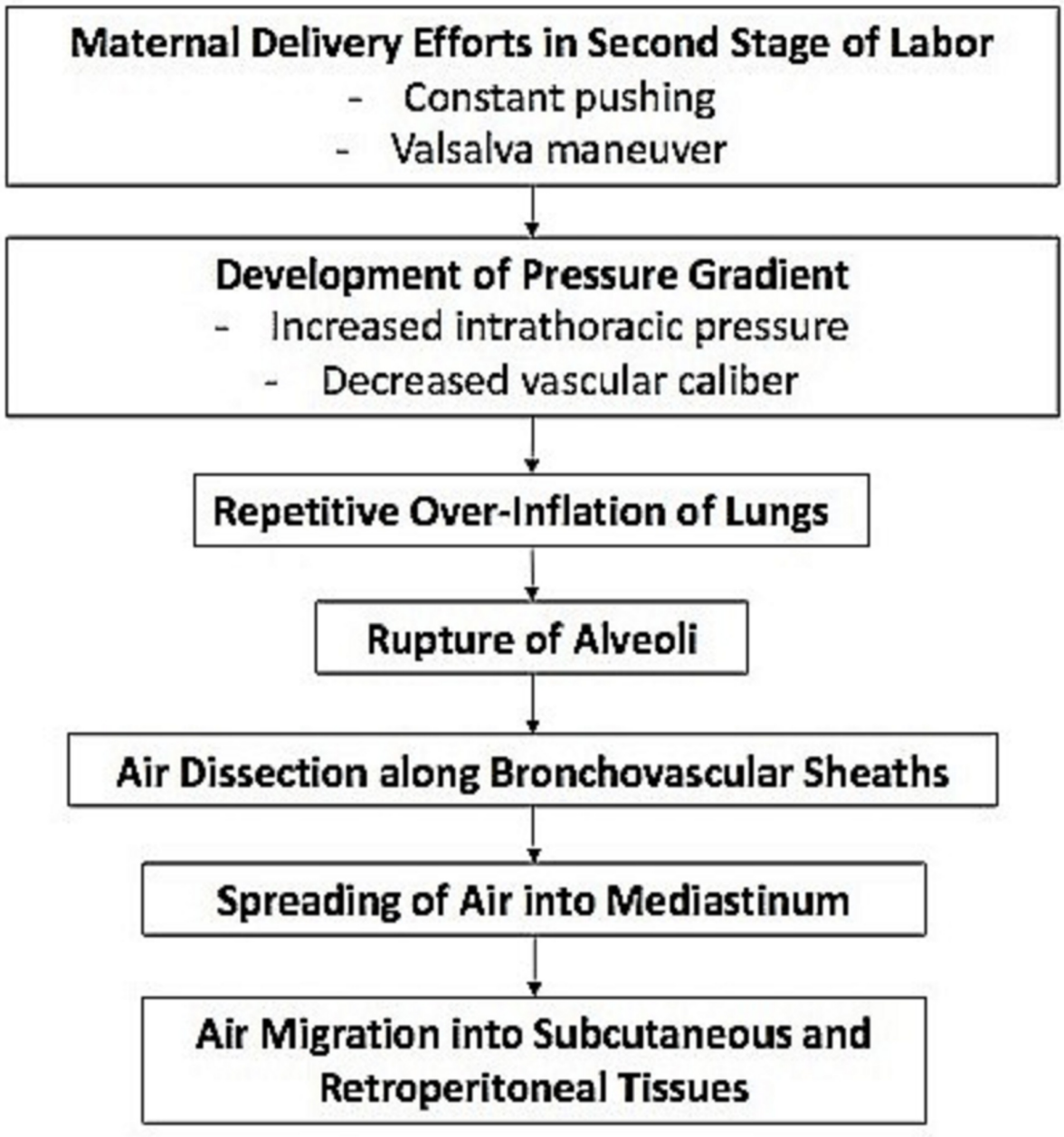

FIGURE 3: The proposed pathophysiologic process of spontaneous pneumomediastinum in pregnancy

In addition to the "pushing" associated with the delivery of the fetus, other physiological alterations of the respiratory system occur during the latter parts of pregnancy. These changes are mainly the consequence of the progestin stimulation of the respiratory drive and consist of a reduction in the functional residual capacity and an increase of about $70 \%$ in alveolar ventilation due to a breathing pattern with augmented respiratory rate and tidal volume. This may also contribute to the development of SPM [12]

\section{Clinical characteristics}

Our literary search methodology resulted in a total of 34 cases of pregnancy or labor-related spontaneous pneumomediastinum, which have been presented in Table 1 [5,13-41]. From our results, we have focused on certain patient characteristics, such as the duration of the pregnancy, parity, smoking history, as well as presenting signs and symptoms. SPM in pregnancy is typically seen in young patients; of the cases we have examined, the average age was $23.4+/-5.7$ years of age. The majority of patients were nonsmokers without a previous history of asthma, showing that the diagnosis can be designated as "spontaneous" due to the unclear etiology.

\begin{tabular}{|c|c|c|c|c|}
\hline Author & Age & Parity & Stage of Labor & $\begin{array}{l}\text { Duration of Labor } \\
\text { (hours) }\end{array}$ \\
\hline Crean et al. 1981 [5] & $22 \mathrm{y} / \mathrm{o}$ & $1^{\text {st }}$ & $2^{\text {nd }}$ stage & 12 \\
\hline Hubbert et al. 1981 [13] & $17 \mathrm{y} / \mathrm{o}$ & N/A & $2^{\text {nd }}$ stage & N/A \\
\hline
\end{tabular}

Duration of Pregnancy (weeks)

N/A

N/A
Treatment

Oxygen

Oxygen, fentanyl, diazepam, \& succinycholine 


\section{Cureus}

\begin{tabular}{|c|c|c|c|c|c|c|}
\hline & $18 \mathrm{y} / \mathrm{o}$ & N/A & $2^{\text {nd }}$ stage & N/A & $\mathrm{N} / \mathrm{A}$ & Oxygen \\
\hline \multirow{2}{*}{ Karson et al. 1984 [14] } & $20 \mathrm{y} / \mathrm{o}$ & $1^{\text {st }}$ & $1^{\text {st }}$ stage & N/A & 9 & Pyridoxine $2 x$ daily \\
\hline & $20 \mathrm{y} / \mathrm{o}$ & $1^{\text {st }}$ & $1^{\text {st }}$ stage & N/A & 42 & None \\
\hline Jensen et al. 1987 [15] & $24 \mathrm{y} / \mathrm{o}$ & $1^{\text {st }}$ & $2^{\text {nd }}$ stage & 10.5 & 41 & Oxygen \\
\hline $\begin{array}{l}\text { Ramirez-Rivera et al. } \\
1990[16]\end{array}$ & $15 \mathrm{y} / \mathrm{o}$ & ${ }_{1} \mathrm{ST}$ & $2^{\text {nd }}$ stage & 14 & $\mathrm{~N} / \mathrm{A}$ & Oxygen \\
\hline $\begin{array}{l}\text { Jayran-Nejad et al. } \\
1993[17]\end{array}$ & $18 \mathrm{y} / \mathrm{o}$ & $1^{\text {st }}$ & $2^{\text {nd }}$ stage & 15.6 & 42 & Analgesia \\
\hline Seidl et al. 1994 [18] & $23 \mathrm{y} / \mathrm{o}$ & $2^{\text {nd }}$ & N/A & N/A & 42 & None \\
\hline Gocmen et al. 1997 [19] & $17 \mathrm{y} / \mathrm{o}$ & $1^{\text {st }}$ & N/A & 11 & 39 & $\begin{array}{l}\text { Symptomatic management \& } \\
\text { monitoring }\end{array}$ \\
\hline $\begin{array}{l}\text { Shyamsunder et al. } \\
1999[20]\end{array}$ & $18 \mathrm{y} / \mathrm{o}$ & $2^{\text {nd }}$ & $2^{\text {nd }}$ stage & N/A & 6 & None \\
\hline Gorbach et al. 1997 [21] & $21 \mathrm{y} / \mathrm{o}$ & N/A & $2^{\text {nd }}$ stage & 4 & 9 & IV Fluids, Promethazine \\
\hline Raley et al. 1997 [22] & N/A & N/A & N/A & N/A & 41 & Oxygen \\
\hline $\begin{array}{l}\text { Dhrampal et al. } 2001 \\
\text { [23] }\end{array}$ & $36 \mathrm{y} / \mathrm{o}$ & N/A & $2^{\text {nd }}$ stage & N/A & 37 & Oxygen \& analgesia \\
\hline \multirow{2}{*}{$\begin{array}{l}\text { Sutherland et al. } 2002 \\
\text { [24] }\end{array}$} & $32 \mathrm{y} / \mathrm{o}$ & $1^{\text {st }}$ & $2^{\text {nd }}$ stage & 8 & N/A & None \\
\hline & $22 \mathrm{y} / \mathrm{o}$ & $1^{\text {st }}$ & $2^{\text {nd }}$ stage & 13 & $\mathrm{~N} / \mathrm{A}$ & None \\
\hline Miguil et al. 2004 [25] & $19 \mathrm{y} / \mathrm{o}$ & N/A & $2^{\text {nd }}$ stage & N/A & 40 & Oxygen \& analgesia \\
\hline Balkan et al. 2006 [26] & $25 \mathrm{y} / \mathrm{o}$ & $1^{\text {st }}$ & $2^{\text {nd }}$ stage & N/A & 36 & Oxygen \\
\hline Bonin et al. 2006 [10] & $27 \mathrm{y} / \mathrm{o}$ & $1^{\text {st }}$ & $2^{\text {nd }}$ stage & 6 & 38 & $\begin{array}{l}\text { Lorazepam for anxiety; anxiolytics } \\
\text { for dyspnea }\end{array}$ \\
\hline North et al. 2006 [27] & $32 \mathrm{y} / \mathrm{o}$ & N/A & $2^{\text {nd }}$ & N/A & N/A & Laxatives \\
\hline Yadav et al. 2008 [28] & $21 \mathrm{y} / \mathrm{o}$ & $1^{\text {st }}$ & $2^{\text {nd }}$ stage & 1.3 & $\mathrm{~N} / \mathrm{A}$ & Oxygen \& analgesics \\
\hline Mahboob et al. 2008 [9] & $24 \mathrm{y} / \mathrm{o}$ & N/A & $2^{\text {nd }}$ stage & N/A & 39 & Oral antibiotics \\
\hline $\begin{array}{l}\text { Zapardiel et al. } 2009 \\
\text { [29] }\end{array}$ & $29 \mathrm{y} / \mathrm{o}$ & $1^{\text {st }}$ & $\begin{array}{l}4^{\text {th }} \text { stage - } \\
\text { only time }\end{array}$ & 7 & 39 & Oxygen \\
\hline $\begin{array}{l}\text { Speksnijder et al. } 2010 \\
\text { [30] }\end{array}$ & $15 \mathrm{y} / \mathrm{o}$ & N/A & $2^{\text {nd }}$ stage & N/A & 28 & $\begin{array}{l}\text { Insulin, fluid, \& potassium } \\
\text { supplementation }\end{array}$ \\
\hline Beynon et al. 2011 [31] & $18 \mathrm{y} / \mathrm{o}$ & $1^{\text {st }}$ & $2^{\text {nd }}$ stage & 4.3 & $39+2$ & Antibiotics \& analgesia \\
\hline Wozniak et al. 2011 [32] & $20 \mathrm{y} / \mathrm{o}$ & N/A & $2^{\text {nd }}$ stage & N/A & 41 & Observation \\
\hline Shrestha et al. 2011 [33] & $19 \mathrm{y} / \mathrm{o}$ & $1^{\text {st }}$ & $2^{\text {nd }}$ stage & N/A & 36 & None \\
\hline Kuruba et al. 2011 [34] & $32 \mathrm{y} / \mathrm{o}$ & $2^{\text {nd }}$ & $2^{\text {nd }}$ stage & 1.5 & 40 & None \\
\hline $\begin{array}{l}\text { McGregor et al. } 2011 \\
{[35]}\end{array}$ & $27 \mathrm{y} / \mathrm{o}$ & $1^{\text {st }}$ & $2^{\text {nd }}$ stage & 1.5 & 40 & Oxygen \& analgesia \\
\hline Khoo et al. 2012 [36] & $33 \mathrm{y} / \mathrm{o}$ & $1^{\text {st }}$ & $2^{\text {nd }}$ stage & 12 & 40 & Analgesia \& best rest \\
\hline Kouki et al. 2013 [37] & $23 \mathrm{y} / \mathrm{o}$ & $1^{\text {st }}$ & $2^{\text {nd }}$ stage & 9 & 40 & Oxygen \& analgesics and sedatives \\
\hline Cho et al. 2015 [38] & $28 \mathrm{y} / \mathrm{o}$ & ${ }_{1} \mathrm{ST}$ & $2^{\text {nd }}$ stage & 5 & 36 & Oxygen \& analgesics \\
\hline Scala et al. 2016 [39] & $30 \mathrm{y} / \mathrm{o}$ & N/A & N/A & N/A & 40 & None \\
\hline $\begin{array}{l}\text { Nagarajan et al. } 2017 \\
\text { [40] }\end{array}$ & $30 \mathrm{y} / \mathrm{o}$ & N/A & $2^{\text {nd }}$ stage & N/A & 41 & Observation \\
\hline
\end{tabular}




\section{Cureus}

\section{TABLE 1: Summary of spontaneous pneumomediastinum cases in pregnancy}

\section{Parity}

Parity was of interest in this patient population, as it has been reported that the second stage of labor is prolonged in a nulliparous woman as compared to a multiparous woman. In a study by Albers et al., it was found that the mean length of the second stage of labor in nulliparas was 54 minutes versus 18 minutes for multiparas [42]. Of the cases we have reviewed and the ones that have provided a parity status, it was found that 20/34 (58.8\%) of cases were of women who were primiparas. It appears as if subsequent pregnancies are not as affected, as only $3 / 34$ (8.8\%) were observed to be in second pregnancies and beyond.

Pregnancy Duration and Delivery

As the majority of cases described are associated with pregnancy, the authors felt it necessary to analyze the duration of pregnancy among all cases. Cases that did not provide the duration of pregnancy or in the cases of early termination or fetal demise, duration of pregnancy was not considered. Of the cases that were reviewed, it was determined that the average length of pregnancy was $39.04+/-2.94$ weeks. This is in line with previously reported works that reported that pregnancy-associated SPM most commonly occurs in the setting of full-term vaginal births [5]. Pregnancy-associated SPM is almost always seen in the setting of natural vaginal delivery, the pathophysiology of which has been discussed above. In very few cases, SPM in pregnancy has been seen in the first and fourth stages of labor, with 28 (80\%) of cases occurring in the second stage of labor.

Signs and Symptoms

Spontaneous pneumomediastinum, in general, presents with similar signs and symptoms among patients. The most commonly reported symptom is chest pain, followed by dyspnea [2]. Here, we focused on spontaneous pneumomediastinum presented during pregnancy. Of the cases that were reported, a summary of presenting clinical signs and symptoms has been shown in Table 2 .

\section{Signs \& Symptoms}

Swelling \& Subcutaneous Emphysema (face, neck, etc.)

Dyspnea

Chest Pain

Crepitus

Tachycardia

Vomiting

Cough
Number of Cases (\%)

$21(60.0)$

$16(45.7)$

$13(37.1)$

$10(28.6)$

$7(20.0)$

$5(14.3)$

$3(8.6)$

\section{TABLE 2: Clinical signs and symptoms of pregnancy-associated SPM}

Although not in the situation of pregnant patients, SPM has been reported due to straining exercises, which also involve the Valsalva maneuver, and forceful coughing. It additionally has been reported in patients with a history of asthma, chronic obstructive pulmonary disease (COPD), and upper respiratory infection [2].

\section{Management and complications}

Spontaneous pneumomediastinum, in general, is not often included in the differential diagnosis and even more so in the setting of pregnancy due to its vague presentation. It is often treated as another causative factor of chest pain, dyspnea, and wheezing, such as asthma exacerbation. SPM usually follows a benign course and management is often conservative. The majority of patients admitted to the hospital with a diagnosis of SPM are treated with analgesics, rest, oxygen therapy, bronchodilators, and occasionally 
antibiotic treatment $[2,43]$. If any pre-disposing condition (asthma, infection, airway obstruction, etc.) is responsive to pharmacological management, then SPM is self-limiting [2,44]. A diagnostic algorithm has been provided in Figure 4.

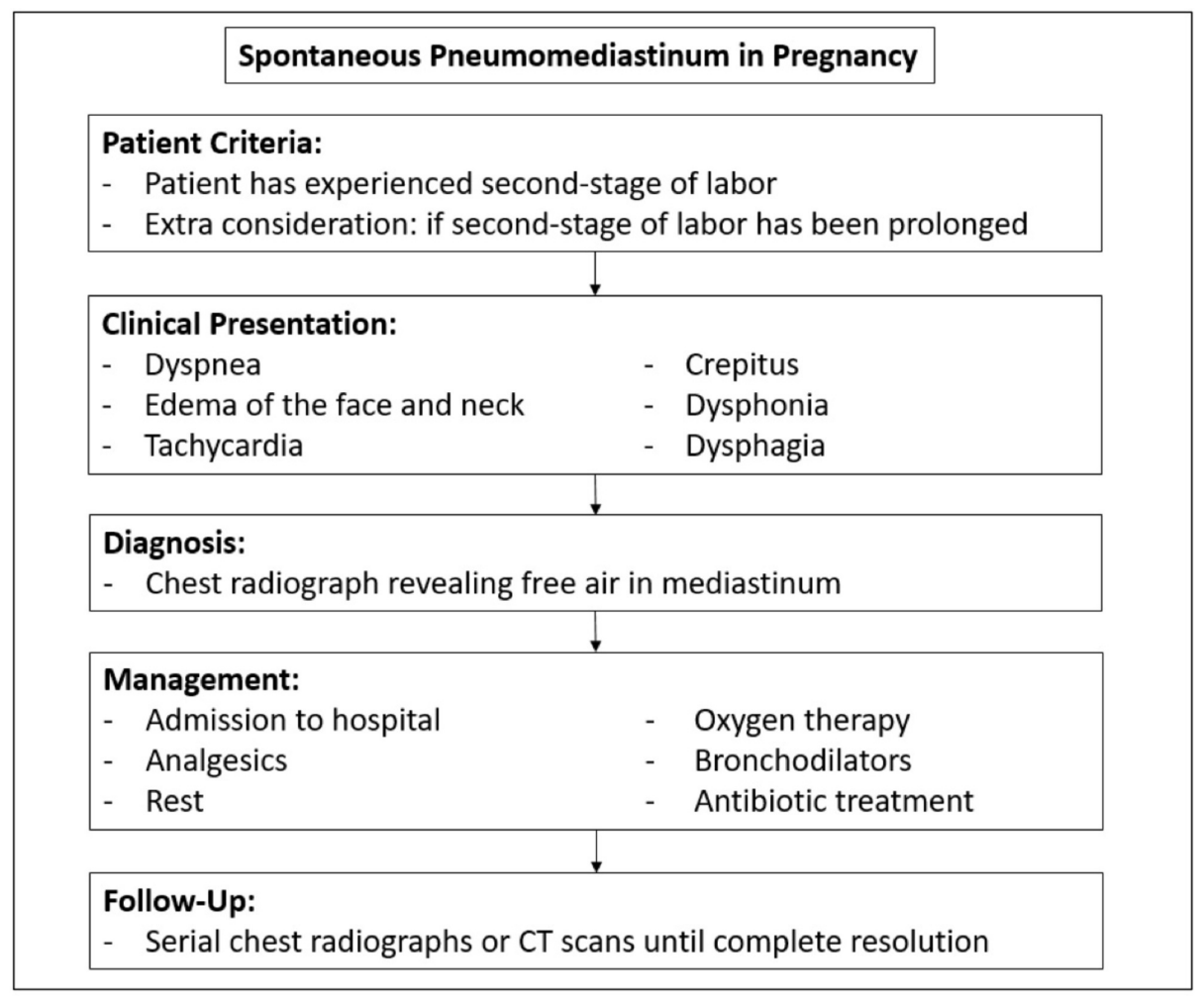

\section{FIGURE 4: Diagnostic and management algorithm of SPM in pregnancy}

SPM: spontaneous pneumomediastinum

Complications of SPM are rare as the diagnosis is often expeditious due to an often overly ominous presentation. Timely management is important to avert any serious complications. If untreated or not monitored, SPM has shown a possibility to convert to tension or malignant PM, which may lead to a compression of the great vessels, ultimately having a deleterious effect on the fetus in the setting of pregnancy [7]. Mortality is extremely rare, as it is known that spontaneous pneumomediastinum typically resolves quickly by the free air being absorbed into the surrounding tissue. In the 34 cases we observed, there were no reports of complications and all cases were managed conservatively.

\section{Conclusions}

Spontaneous pneumomediastinum is a rare occurrence in the physiologic setting of pregnancy, labor, and delivery. It is thought the Valsalva maneuver produced in natural vaginal delivery and its physiologic consequences are the impetus for the development of SPM. A review of case reports in the literature revealed that a majority of patients are primiparas, of a younger age, and have term or longer durations of pregnancy. As the literature suggests, the second stage of labor is most commonly associated with the development of SPM. The cases reviewed are associated with the most common clinical signs and symptoms of SPM such as chest pain and dyspnea. Once diagnosed, patients should be admitted to the hospital, monitored, treated with analgesics, rest, and oxygen therapy until complete or near resolution. Once released from the hospital, patients may be followed with serial chest radiographs or CT scans until complete resolution. Physicians need to be aware of the possibility of SPM in parturient patients and include SPM in the differential, especially in the setting of dyspnea, chest pain, and relevant physical findings.

\section{Additional Information \\ Disclosures}

Conflicts of interest: In compliance with the ICMJE uniform disclosure form, all authors declare the following: Payment/services info: All authors have declared that no financial support was received from any organization for the submitted work. Financial relationships: All authors have declared that they have no financial relationships at present or within the previous three years with any organizations that might 
have an interest in the submitted work. Other relationships: All authors have declared that there are no other relationships or activities that could appear to have influenced the submitted work.

\section{References}

1. Roguin A: Rene Theophile Hyacinthe Laennec (1781-1826): the man behind the stethoscope . Clin Med Res. 2006, 4:230-235. 10.3121/cmr.4.3.230

2. Sahni S, Verma S, Grullon J, Esquire A, Patel P, Talwar A: Spontaneous pneumomediastinum: time for consensus. N Am J Med Sci. 2013, 5:460-464. 10.4103/1947-2714.117296

3. Hamman L: Spontaneous mediastinal emphysema. Bull Johns Hopkins Hosp. 1939, 64:1-21.

4. Macia I, Moya J, Ramos R, et al.: Spontaneous pneumomediastinum: 41 cases . Eur J Cardiothorac Surg. 2007, 31:1110-1114. 10.1016/j.ejcts.2007.03.008

5. Crean PA, Stronge JM, FitzGerald MX: Spontaneous pneumomediastinum in pregnancy. Case report . Br J Obstet Gynaecol. 1981, 88:952-954. 10.1111/j.1471-0528.1981.tb02236.x

6. Macklin CC: Transport of air along sheaths of pulmonic blood vessels from alveoli to mediastinum: clinical implications. Arch Intern Med (Chic). 1939, 64:913-926. 10.1001/archinte.1939.00190050019003

7. Macklin MM, Macklin CC: Malignant interstitial emphysema of the lungs and mediastinum as an important occult complication in many respiratory diseases and other conditions: an interpretation of the clinical literature in the light of laboratory experiment. Medicine. 1944, 23:281-358.

8. Hacker NF, Hobel CJ: Normal labor, delivery, and postpartum care. Essentials of Obstetrics \& Gynecology. Joseph C. Gambone (ed): Saunders, Philadelphia, PA; 2016. 96-125.

9. Mahboob A, Eckford SD: Hamman's syndrome: an atypical cause of postpartum chest pain . J Obstet Gynaecol. 2008, 28:652-653. 10.1080/01443610802378066

10. Bonin MM: Hamman's syndrome (spontaneous pneumomediastinum) in a parturient: a case report [Article in English, French]. J Obstet Gynaecol Can. 2006, 28:128-131. 10.1016/S1701-2163(16)32056-4

11. Majer S, Graber P: Postpartum pneumomediastinum (Hamman's syndrome). CMAJ. 2007, 177:32. 10.1503/cmaj.061581

12. Jamadar DA, Kazerooni EA, Hirschl RB: Pneumomediastinum: elucidation of the anatomic pathway by liquid ventilation. J Comput Assist Tomogr. 1996, 20:309-311.

13. Hubbert CH, Roberson WT, Solomon JA: Spontaneous tension pneumothorax and mediastinal emphysema associated with anesthesia for cesarean section. AANA J. 1981, 49:59-62.

14. Karson EM, Saltzman D, Davis MR: Pneumomediastinum in pregnancy: two case reports and a review of the literature, pathophysiology, and management. Obstet Gynecol. 1984, 64:39S-43S.

15. Jensen H, Asmussen I, Eliasen B: Labor complicated by spontaneous emphysema . Acta Obstet Gynecol Scand. 1987, 66:567-568. 10.3109/00016348709015738

16. Ramirez-Rivera J: Spontaneous pneumomediastinum. Bol Asoc Med P R. 1990, 82:359-361.

17. Jayran-Nejad Y: Subcutaneous emphysema in labour. Anaesthesia. 1993, 48:139-140. 10.1111/j.13652044.1993.tb06853.x

18. Seidl JJ, Brotzman GL: Pneumomediastinum and subcutaneous emphysema following vaginal delivery. Case report and review of the literature. J Fam Pract. 1994, 39:178-180.

19. Göçmen A, Gül T, Sezer FA, Erden AC, Yilmaztürk A: Postpartum subcutaneous emphysema with pneumomediastinum. Zentralbl Gynakol. 1997, 119:86-88.

20. Shyamsunder AK, Gyaw SM: Pneumomediastinum: the Valsalva crunch. Md Med J. 1999, 48:299-302.

21. Gorbach JS, Counselman FL, Mendelson MH: Spontaneous pneumomediastinum secondary to hyperemesis gravidarum. J Emerg Med. 1997, 15:639-643. 10.1016/S0736-4679(97)00142-X

22. Raley JC, Andrews JI: Spontaneous pneumomediastinum presenting as jaw pain during labor . Obstet Gynecol. 2001, 98:904-906.

23. Dhrampal A, Jenkins J: Spontaneous cervical and mediastinal emphysema following childbirth. Anaesthesia. 2001, 56:93-94. 10.1046/j.1365-2044.2001.01840-19.x

24. Sutherland FW, Ho SY, Campanella C: Pneumomediastinum during spontaneous vaginal delivery. Ann Thorac Surg. 2002, 73:314-315. 10.1016/S0003-4975(01)02729-1

25. Miguil M, Chekairi A.: Pneumomediastinum and pneumothorax associated with labour. Int J Obstet Anesth. 2004, 13:117-119. 10.1016/j.ijoa.2003.12.001

26. Balkan ME, Alver G: Spontaneous pneumomediastinum in 3rd trimester of pregnancy . Ann Thorac Cardiovasc Surg. 2006, 12:362-324.

27. North CE, Candelier CK: Spontaneous cervical surgical emphysema and pneumomediastinum: a rare complication of childbirth. J Obstet Gynaecol. 2006, 26:571-572. 10.1080/01443610600821739

28. Yadav Y, Ramesh L, Davies JA, Nawaz H, Wheeler R: Gross spontaneous pneumomediastinum (Hamman's syndrome) in a labouring patient. J Obstet Gynaecol. 2008, 28:651-652. 10.1080/01443610802378058

29. Zapardiel I, Delafuente-Valero J, Diaz-Miguel V, Godoy-Tundidor V, Bajo-Arenas JM: Pneumomediastinum during the fourth stage of labor. Gynecol Obstet Invest. 2009, 67:70-72. 10.1159/000162103

30. Speksnijder L, Duvekot JJ, Duschek EJ, Jebbink MC, Bremer HA: Spontaneous pneumomediastinum: a rare presentation of diabetic ketoacidosis in a pregnant woman. Obstet Med. 2010, 3:158-160. 10.1258/om.2010.100028

31. Beynon F, Mearns S: Spontaneous pneumomediastinum following normal labour. BMJ Case Rep. 2011, 10.1136/bcr.07.2011.4556

32. Wozniak DR, Blackburn A: Postpartum pneumomediastinum manifested by surgical emphysema. Should we always worry about underlying oesophageal rupture?. BMJ Case Rep. 2011, 10.1136/bcr.04.2011.4137

33. Shrestha A, Acharya S: Subcutaneous emphysema in pregnancy. JNMA J Nepal Med Assoc. 2011, 51:141-143. 10.31729/jnma.39

34. Kuruba N, Hla TT: Postpartum spontaneous pneumomediastinum and subcutaneous emphysema: Hamman's syndrome. Obstet Med. 2011, 4:127-128. 10.1258/om.2011.110038

35. McGregor A, Ogwu C, Uppal T, Wong MG: Spontaneous subcutaneous emphysema and pneumomediastinum during second stage of labour. BMJ Case Rep. 2011, 10.1136/bcr.04.2011.4067 


\section{Cureus}

36. Khoo J, Mahanta VR: Spontaneous pneumomediastinum with severe subcutaneous emphysema secondary to prolonged labor during normal vaginal delivery. Radiol Case Rep. 2012, 7:713. 10.2484/rcr.v7i3.713

37. Kouki S, Fares AA: Postpartum spontaneous pneumomediastinum 'Hamman's syndrome'. BMJ Case Rep. 2013, 10.1136/bcr-2013-010354

38. Cho C, Parratt JR, Smith S, Patel R: Spontaneous pneumomediastinum (Hamman's syndrome): a rare cause of postpartum chest pain. BMJ Case Rep. 2015, 10.1136/bcr-12-2010-3603

39. Scala R, Madioni C, Manta C, Maggiorelli C, Maccari U, Ciarleglio G: Spontaneous pneumomediastinum in pregnancy: A case report. Rev Port Pneumol (Eng). 2016, 22:129-31. 10.1016/j.rppnen.2015.09.004

40. Nagarajan DB, Ratwatte MD, Mathews J, Siddiqui M: Intrapartum spontaneous pneumomediastinum and surgical emphysema (Hamman's syndrome) in a 30-year-old woman with asthma. BMJ Case Rep. 2017, 10.1136/bcr-2017-219223

41. Berdai MA, Benlamkadem S, Labib S, Harandou M: Spontaneous pneumomediastinum in labor . Case Rep Obstet Gynecol. 2017, 2017:6235076. 10.1155/2017/6235076

42. Albers LL: The duration of labor in healthy women . J Perinatol. 1999, 19:114-119.

43. Abolnik I, Lossos IS, Breuer R: Spontaneous pneumomediastinum. A report of 25 cases . Chest. 1991, 100:9395. 10.1378/chest.100.1.93

44. Steffey WR, Cohn AM: Spontaneous subcutaneous emphysema of the head, neck, and mediastinum . Arch Otolaryngol. 1974, 100:32-35. 10.1001/archotol.1974.00780040036007 